\title{
DIGITAL CURATION DI UPT PERPUSTAKAAN JENDERAL SOEDIRMAN
}

\author{
Aris Kurniawan*, Supriyana, Saino, Dwiana Enimawati, Susiach \\ UPT Perpustakaan Universitas Jenderal Soedirman \\ *Korespondensi: ariskurniawanlib@gmail.com
}

Diajukan: 02-11-2017; Direview: 24-01-2018; Diterima: 08-02-2018; Direvisi: 12-04-2018

\begin{abstract}
This study discusses the digital curation in Unsoed Library Unit. Digital curation is an ongoing process of digital collection management activities. The purpose of this research is to know the process of management and handling of digital collection of thesis in terms of Digital Curation Center (DCC) Life Cycle Model. The benefits of this research are as material evaluation of the management of digital document objects, and as reference in the formulation of policies and legal basis needed in the management of digital collections in Unsoed Library Unit. This research uses descriptive qualitative method that is by doing depiction using word and language from perception and action performed by librarian. Based on the data obtained through interviews, expert observation and consultation, digital curation cycle already exists in Unsoed Library Unit. However, there is still a need to strengthen the legal basis, renewal of standard operating procedures, facilities, and understanding of digital curation.
\end{abstract}

\begin{abstract}
ABSTRAK
Penelitian ini membahas digital curation di UPT Perpustakaan Unsoed. Digital Curation merupakan proses lanjutan dari kegiatan pengelolaan koleksi digital. Tujuan penelitian ini untuk mengetahui proses kegiatan pengelolaan dan penanganan koleksi digital skripsi dan tesis ditinjau dari Digital Curation Centre (DCC) Life Cycle Model. Manfaat penelitian ini sebagai bahan evaluasi terhadap pengelolaan objek dokumen digital, serta sebagai acuan dalam perumusan kebijakan dan dasar hukum yang dibutuhkan dalam pengelolaan koleksi digital di UPT Perpustakaan Unsoed. Penelitian ini menggunakan metode kualitatif deskriptif, yaitu dengan melakukan penggambaran menggunakan kata dan bahasa dari persepsi dan tindakan yang dilakukan oleh pustakawan. Berdasarkan data yang diperoleh melalui wawancara, observasi dan konsultasi ahli, siklus digital curation sudah ada di UPT Perpustakaan Unsoed. Namun masih diperlukan penguatan dasar hukum, pembaharuan standar operasional prosedur, sarana prasarana, serta pemahaman tentang digital curation.
\end{abstract}

Keywords: Digital curation; Digital collection; DDC life cycle model; Library

\section{PENDAHULUAN}

Pertumbuhan koleksi digital dewasa ini berkembang sangat pesat. Informasi yang tersaji secara digital mempunyai bentuk yang beragam berupa teks, gambar, video, audio, atau bentuk informasi digital lain. Keberagaman media dan peningkatan kuantitas koleksi digital membutuhkan manajemen koleksi digital yang rapi dan berkelanjutan agar nilai informasi dan aksesnya dapat dimanfaatkan dalam jangka waktu yang lama. Jangkauan yang luas terhadap koleksi perpustakaan memberikan keleluasaan bagi pemustaka mengakses kapan dan di mana saja. Perpustakaan melakukan kegiatan pengkayaan serta mengalihbentukkan koleksi menjadi dokumen digital merupakan bagian dari memperluas jangkuan akses perpustakaan. Proses yang terus menerus atau berlanjut terhadap kegiatan mengelola koleksi digital yang harus dijaga dan memungkinkan untuk selalu tersedia serta dapat dimanfaatkan kembali oleh pengguna merupakan pengertian dari digital curation.

Perpustakaan memiliki langkah yang berbeda-beda dalam proses pengelolaan dan pengadaan koleksi, digitalisasi koleksi, preservasi, konservasi, dan penyimpanan koleksi 
digital. Terdapat beberapa teori dan konsep pengelolaan koleksi digital yang dapat menjadi acuan dalam manajemen koleksi digital. Perpustakaan membuat tahapan sendiri dengan dan/atau tanpa merujuk pada teori yang mengacu pada kebiasaan yang telah dilakukan, kemudian dituangkan dalam regulasi dan standar operasional prosedur (SOP).

Saat ini Unit Pelaksana Teknis (UPT) Perpustakaan Universitas Jenderal Soedirman Purwokerto (selanjutnya disebut UPT Perpustakaan Unsoed) telah memiliki lebih dari 28.000 koleksi digital, diantaranya skripsi, tesis, jurnal, e-book, dan laporan penelitian. Koleksi tersebut dilayankan melalui web dengan jaringan intranet (lokal) dan pemustaka dapat mengakses layanan e-resources melalui computer yang disediakan perpustakaan.

Penelitian ini membahas pengelolaan objek dokumen digital koleksi skripsi dan tesis UPT Perpustakaan Unsoed, yang mengacu pada SOP. SOP pengelolaan koleksi digital ini dibuat pada tahun 2011 dan sampai sekarang belum dilakukan review untuk perbaikan. Seiring dengan perkembangan beberapa aspek teknologi informasi, tata kelola organisasi dan bidang keilmuan perpustakaan, akan terjadi ketimpangan dalam menjalankan SOP. Penelitian ini membahas tentang bagaimana proses kegiatan mengelola objek digital di UPT Perpustakaan Unsoed? yang dilakukan melalui benchmarking dengan kosep dan teori digital curation.

\section{TINJAUAN PUSTAKA}

\subsection{Digital Curation}

Pennock (2007) mengatakan bahwa digital curation, broadly interpreted, is about maintaining and adding value to a trusted body of digital information for both current and future use: in other words, it is the active management and appraisal of digital information over its entire life cycle digital curation. Menurut Priyanto (2013) kurasi digital adalah sebuah proses yang terus menerus terhadap kegiatan mengelola objek dokumen digital (dokumen digital dan tercipta secara digital) yang harus dijaga dan memungkinkan untuk selalu tersedia serta dapat dimanfaatkan kembali oleh pengguna. Seorang kurator digital sangat memberikan nilai tambah bagi institusi untuk menjamin kontinuitas pemanfaatan data dan ketersediaan objek digital.

\subsection{Lifecycle Model}

Salah satu lembaga yang memiliki kegiatan digital curation adalah Digital Curation Centre (DCC) di Inggris. DDC merupakan sebuah lembaga pengembangan keahlian dalam kegiatan kurasi informasi digital. Kegiatan ini memfokuskan pada peningkatan kapasitas, kemampuan, dan keterampilan untuk pengelolaan data penelitian pada komunitas riset pendidikan tinggi di Inggris. Lembaga ini memberikan dukungan dan memberikan saran keahlian serta bantuan praktis kepada siapapun di lingkungan pendidikan tinggi dan peneliti di Inggris yang ingin menyimpan, mengelola, dan melindungi berbagai data penelitian secara digital (Narendra, 2014).

Digital curation life cycle model dapat digunakan untuk merencanakan kegiatan dalam sebuah organisasi untuk memastikan tahap yang perlu dilakukan serta memastikan setiap tahap berurutan secara benar. Proses kegiatan dalam alur kerja kurasi digital dijelaskan sebagai berikut.

1) Conceptualize, merupakan tahap perencanaan kegiatan pengumpulan data. Kegiatan ini mencakup penetapan objek digital yang dipilih, metode pengambilan objek, dan pilihan media penyimpanan.

2) Create or receive. Create membuat data termasuk metadata administratif, deskriptif, 
struktural, dan teknis. Metadata pelestarian juga dapat ditambahkan pada saat pembuatan. Receive menerima data, sesuai dengan kebijakan pengumpulan yang didokumentasikan, dari pembuat data, arsip, repositori, atau pusat data lainnya. Tahap ini untuk memastikan bahwa semua data dilengkapi dengan metadata administratif, deskriptif, struktural, dan teknis yang memadai. Idealnya data sudah dilengkapi dengan kelengkapan data. Namun, peneliti dan repositori bekerja dengan standar yang berbeda sehingga harus disesuaikan dengan kebijakan lokal.

3) Appraise and select, merupakan tahap mengevaluasi dan memilih data untuk dapat digunakan dalam jangka panjang disesuaikan dengan pedoman yang terdokumentasi, kebijakan, atau persyaratan hukum. Beberapa data dapat dibuang (dispose) karena dinilai rusak atau tidak bernilai, serta dapat dilakukan pemindahan objek digital ke kustodian. Dispose adalah kegiatan memisahkan objek digital yang memang tidak digunakan karena informasinya tidak bernilai jangka panjang. Untuk itu perlu adanya kebijakan dan peraturan dalam pendokumentasian.

4) Ingest atau inputing, merupakan kegiatan memasukkan data ke dalam repositori digital institusi dan pusat data lainnya. Dalam hal ini ada keterkaitan antara form input dalam aplikasi sesuai dengan standar metadata.

5) Preservation action, merupakan kegiatan yang dikelola untuk memastikan akses berkelanjutan ke materi digital selama diperlukan. Pelestarian digital didefinisikan secara luas dan mengacu pada semua tindakan yang diperlukan untuk mempertahankan akses ke materi digital di luar batas kegagalan media atau perubahan teknologi dan organisasi. Aktivitas tersebut seperti kontrol kualitas, pembuatan katalog, klasifikasi, pemetaan data, ketepatan, pendaftaran metadata semantik dan struktural. Ada beberapa tahapan yang mengikuti dalam tindakan preservasi, yaitu: (1) reappraise, kegiatan menilai kembali objek digital yang mungkin mengalami kesalahan dan gagal dalam pemeriksaan kontrol kualitas; (2) migrate, kegiatan mengalihkan objek digital ke format yang berbeda, baik untuk menormalkannya di dalam sistem maupun untuk mengurangi risiko yang timbul dari perangkat keras atau keusangan.

Proses digital curration life cycle model ini juga dijelaskan pada Gambar 4.

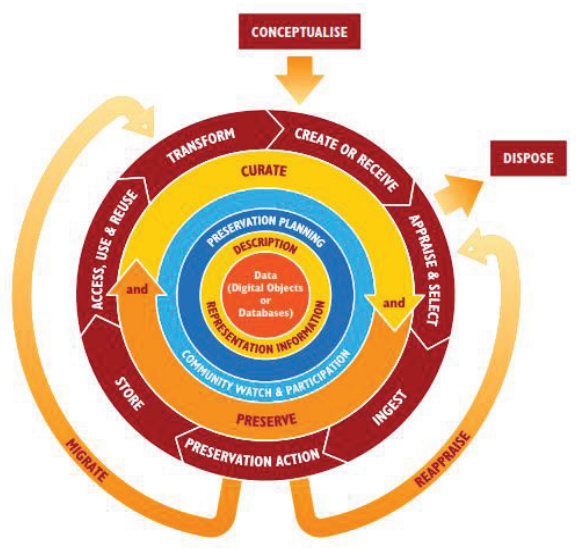

Gambar 1. Digital curation life cycle (Ball, 2010)

Dalam Digital Preservation Handbook Glossary yang dikembangkan oleh Digital Preservation Coalition dijelaskan definisi pelestarian jangka pendek, menengah, dan panjang sebagai berikut: 
- pelestarian jangka pendek, akses ke materi digital untuk jangka waktu tertentu sampai menjadi tidak dapat diakses karena adanya perubahan teknologi;

- pelestarian jangka menengah, akses terus menerus ke materi digital dengan mengikuti perubahan teknologi untuk jangka waktu tertentu;

- pelestarian jangka panjang, akses terus menerus ke materi digital, disertai dengan nilai informasi yang terkandung di dalamnya.

Ploszajski (2017) menyebutkan bahwa dalam praktek preservasi digital, jangka pendek dan menengah jarang dilakukan. Namun, di Polandia ada beberapa informasi yang harus dipelihara dalam beberapa periode waktu karena ada kewajiban hukum untuk menyimpan beberapa jenis dokumen, misalnya data dan koleksi tesis yang harus dilestarikan selama 50 tahun. Proses pelestarian koleksi tersebut dengan tiga pertimbangan, yaitu:

1) Store, mengacu pada komitmen awal terhadap penyimpanan data, ada berbagai tindakan jangka panjang untuk memastikan data tetap aman;

2) Access use and reuse, tahap ini difokuskan untuk menjaga agar data dapat ditemukan dan diakses oleh pengguna. Hal ini meliputi memunculkan metadata deskriptif melalui antarmuka dan memastikan pelestarian metadata yang dimiliki agar data terus memenuhi persyaratan pengguna.

3) Transform, membuat objek digital yang baru dari objek aslinya, misalnya dengan migrasi ke bentuk/objek yang berbeda.

\section{METODE}

Jenis penelitian ini adalah kualitatif-deskriptif, yaitu penelitian yang bertujuan untuk memahami fenomena yang dialami oleh subjek penelitian, misalnya perilaku, persepsi, motivasi, dan tindakan secara holistic dengan cara deskripsi dalam bentuk kata-kata dan bahasa, pada suatu konteks khusus yang alamiah dan dengan memanfaatkan berbagai metode alamiah (Moleong, 2007). Penelitian ini menggunakan metode penggambaran menggunakan kata dan bahasa dari persepsi dan tindakan yang dilakukan pustakawan. Pengumpulan data dilakukan dengan wawancara, observasi langsung, dan dokumentasi. Informan berjumlah 5 orang yang terdiri dari Kepala UPT Perpustakaan, 3 orang bagian teknologi informasi, dan 1 orang bagian pengolahan koleksi. Validitas data dilakukan dengan teknik triangulasi, yaitu teknik pemeriksaan keabsahan data dengan memanfaatkan sesuatu yang lain. Denzin (1978) dalam Moleong (2007) membedakan empat macam triangulasi sebagai teknik pemeriksaan dalam memanfaatkan penggunaan sumber, metode, penyidik, dan teori. Proses diawali dengan pengumpulan data, kondensasi data atau proses memilih, memfokuskan, menyederhanakan, mengabstrakkan kemudian melakukan penyajian data dan penarikan kesimpulan.

\section{HASIL DAN PEMBAHASAN}

\subsection{Layanan E-Resources UPT Perpustakaan Unsoed}

UPT Perpustakaan Unsoed melayankan koleksi dalam bentuk digital, meliputi koleksi skripsi, e-book, laporan, disertasi, dan tesis. Pemustaka dapat mengaksesnya melalui laman http://edoc.unsoed atau IP address server 192.168.30.233 pada komputer yang disediakan di ruang layanan e-resources. Layanan tersebut masih bersifat lokal sehingga hanya dapat diakses di ruang layanan e-resources. Untuk melayankan koleksi digital skripsi, e-book, laporan, disertasi dan tesis, perpustakaan menggunakan web E-doc (aplikasi ini 
dikembangkan sejak tahun 2010).

Pengelolaan aplikasi dan server $E$-doc menjadi tanggung jawab bagian pengembangan teknologi dan sistem informasi perpustakaan. Kegiatan pengelolaannya meliputi maintenance server, backup data, pembuatan user, serta input content. Koleksi yang sudah di-unggah ke Edoc sejumlah 36.959 judul koleksi digital yang terdiri dari skripsi 28.510 judul; tesis 2.081 judul; e-books 24 judul; laporan 6.343 judul; dan disertasi 1 judul. Jumlah objek digital di tiap jenis koleksi skripsi 57.020 file, tesis 4.162 file, e-books 24 file, laporan 12.686 file, dan disertasi 1 file. Objek digital skripsi dan tesis dilayankan dalam bentuk file PDF yang terbagi menjadi 2 file, yaitu abstrak skripsi dan full text skripsi.

\subsection{Siklus Kegiatan Digital Curation}

\section{Conceptualise}

Siklus hidup kurasi yang tepat dimulai dari menetapkan konsep perencanaan kegiatan hingga pengumpulan data. Kegiatan ini meliputi penetapan objek digital yang dipilih, metode pengambilan objek, dan pilihan media penyimpanan. Berdasarkan surat pemberitahuan Kepala Perpustakaan tahun 2017 tentang kewajiban mahasiswa untuk menyerahkan skripsi atau tesisnya ke UPT Perpustakaan Unsoed dengan ketentuan dalam format 1 file PDF. Pemberitahuan tersebut sekaligus sebagai sebuah kewajiban yang harus dipenuhi. Surat tersebut merupakan bagian dari tahap menetapkan metode pengumpulan dan pengambilan data. Koleksi digital tesis diperoleh secara bertahap dari pengelola Pasca-Sarjana Unsoed secara kolektif. Seluruh mahasiswa S2 setiap periode wisuda menyerahkan secara langsung karya tesisnya. Berdasarkan SOP dengan kode SOP 145 Tahun 2011 tentang Pengolahan Skripsi, Tesis, dan Disertasi, bagian Pengolahan Bahan Perpustakaan bertugas menerima, melakukan pengecekan keabsahan dan kelengkapan softcopy skripsi dan tesis.

Tahap ini memerlukan acuan aturan yang lebih kuat, jelas, dan rinci untuk proses pengumpulan koleksi digital yang memuat tentang jumlah, sampul cover, isi file, media penyimpanan, kewenangan penanganan, dan isi dalam media penyimpanan. Hal tersebut juga diterapkan Perpustakaan Universitas Indonesia, yang mana lembaga menetapkan aturan dan acuan yang jelas dalam proses pengumpulan tugas akhir dengan penerbitan SK Rektor dan secara terperinci dijelaskan serta disebarluaskan melalui laman websitenya. Dengan demikian, proses pengumpulan data mempunyai landasan yang kuat untuk memunculkan partisipasi dan kepatuhan dalam pelaksanaannya - tidak akan ada kebingungan dalam proses pengumpulan dan mempermudah dalam pengolahannya.

\section{Create or Recieve}

Data yang telah diterima oleh perpustakaan kemudian diedit berdasarkan SOP 149 Tahun 2011 oleh Bagian Pengolahan Digital sub-kegiatan digitalisasi. Adapun kegiatan yang dilakukan Bagian Pengolahan Digital sebagai berikut:

a) mengkopi file;

b) mengkonversi ke PDF;

c) membuat identitas kepemilikan;

d) memisahkan file fulltext dan abstrak;

e) memperkecil ukuran file PDF;

f) mengunggah metadata dan file PDF ke server.

Metadata teknis tidak dibuat tetapi petugas melakukan penginputan data bibliografi koleksi ke aplikasi perpustakaan sebagai metadata desktiptif. Data yang diserahkan mahasiswa 
tidak dilengkapi dengan metadata teknis maka perlu diimbangi dengan create metadata deskriptif dan/atau pengeditan metadata teknis. Siklus kurasi digital menganjurkan untuk mengedit metadata karena tahap ini penting dalam mengembangkan kurasi digital.

\section{Appraise and Select}

UPT Perpustakaan Unsoed belum melakukan evaluasi koleksi secara rutin. Perpustakaan hanya mengecek koleksi digital pada saat proses penerimaan dengan memastikan file dapat dibuka dan digunakan. Pedoman yang terdokumentasikan serta kebijakan atau persyaratan hukum yang berkaitan dengan proses evaluasi dan dispose belum ada, sehingga berimplikasi pada tidak berjalannya siklus ini secara utuh.

Kegiatan dispose yang terlepas dari rangkaian kegiatan kurasi digital berimplikasi pada tidak diterbitkannya prosedur dan kebijakan peraturan. Hal ini berdampak pada jumlah koleksi digital dan beban server yang semakin bertambah. Sebagai saran, sebaiknya perpustakaan perlu mengidentifikasi manajemen resiko dalam kegiatan preservasi serta melakukan evaluasi terhadap kualitas koleksi digital secara insidental.

\section{Ingest}

E-doc merupakan repositori digital institusi yang berfungsi sebagai pusat data koleksi digital. Pada tahap ini petugas meng-input data bibliografi ke dalam form E-doc. Penggunaan standar metadata diharapkan mampu meningkatkan ketepatan hasil pencarian suatu sumber. Standar metadata yang sering diaplikasikan di perpustakaan adalah dublin core. Dalam Dublin core metadata element set, version 1.1 (2013) terdapat 15 elemen metadata, yaitu contributor, coverage, creator, date, description, format, identifier, language, publisher, relation, rights, source, subject, title dan type.

Merujuk pada standar metadata dublin core maka form E-doc untuk meng-input metadata deskriptif koleksi skripsi dan tesis masih kurang memadai. Beberapa elemen belum ada, yaitu identifier, language, relation, right, dan subject. Selain itu, elemen lain yang belum terdeskripsikan dengan jelas meliputi date, format, coverage, dan publisher. Implikasi dari metadata deskriptif yang kurang lengkap adalah menyulitkan dalam proses searching koleksi melalui E-doc. Pilihan di menu advance search tidak mampu memberikan sortir berdasarkan tahun, program studi, serta subjek. Tabel 1 menunjukkan perbandingan hasil pengamatan antara form input E-doc dengan dublin core.

Tabel 1. Hasil Perbandingan Form E-doc dengan Dublin Core

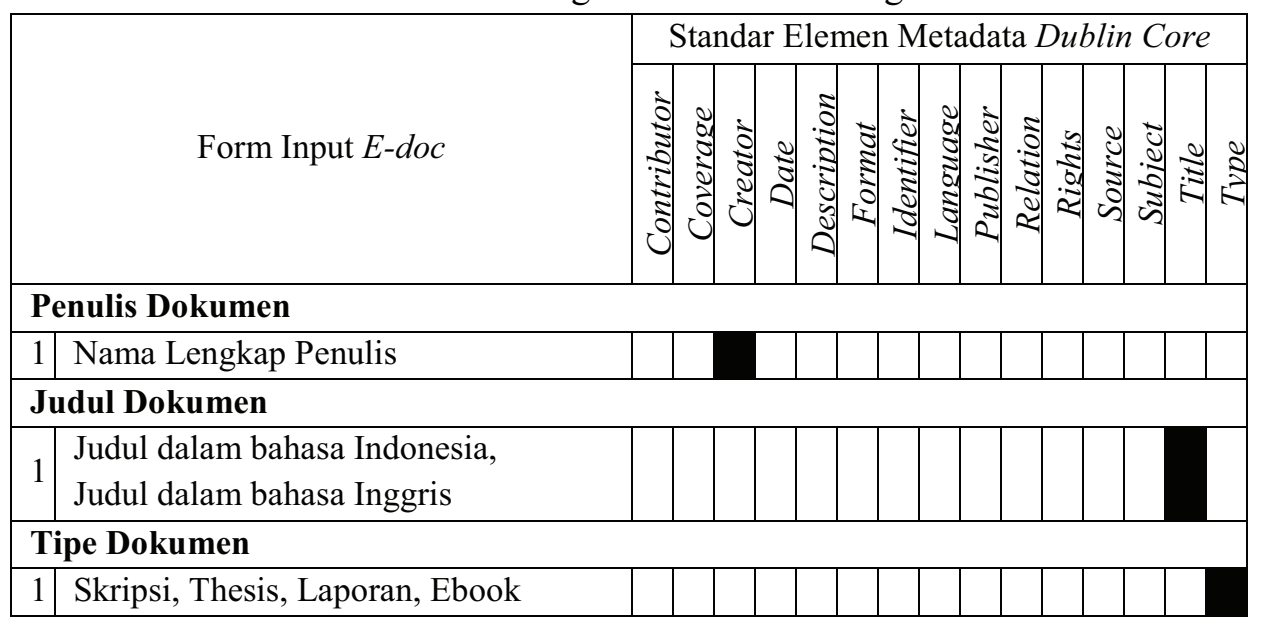




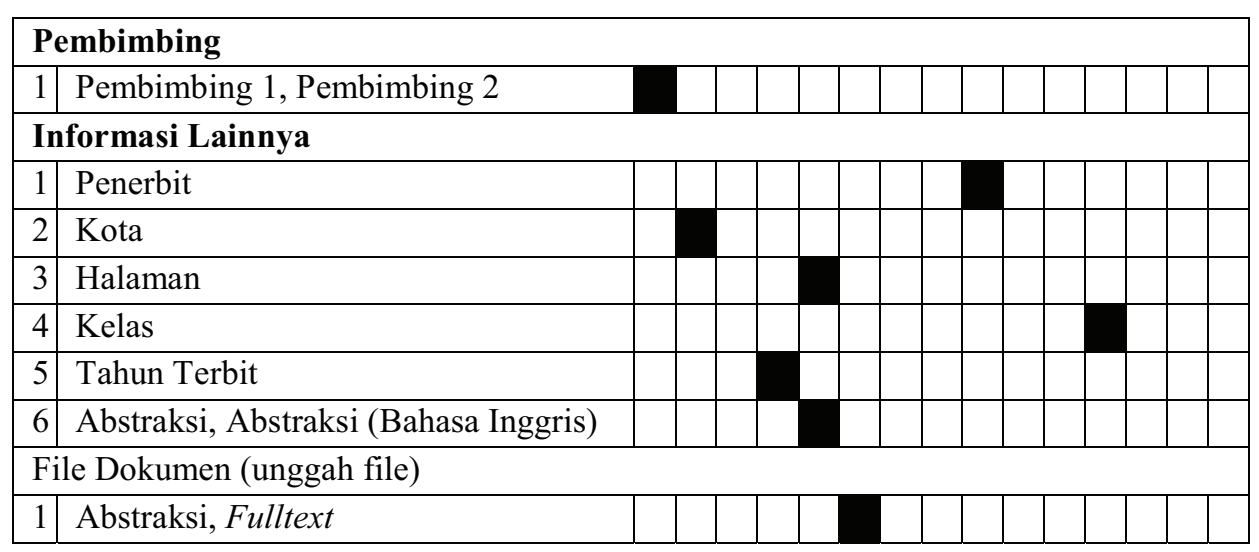

Penginputan ke aplikasi E-doc dilakukan oleh Bagian Pengembangan Teknologi dan Sistem Informasi yang sekaligus bertanggung jawab terhadap pengelolaan aplikasi, server, dan backup data. Gambar 1 menunjukkan alur pengelolaan koleksi digital di UPT Perpustakaan Unsoed.

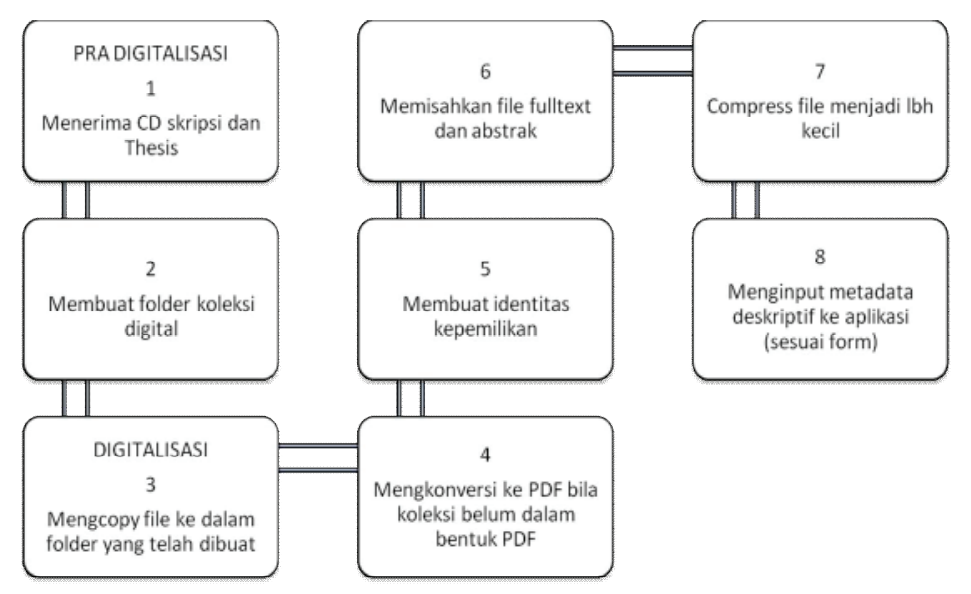

Gambar 1. Alur kegiatan pengelolaan koleksi digital

Sumber: SOP UPT Perpustakaan Unsoed

\section{Preservation Action}

Preservasi koleksi digital tidak hanya dengan cara melestarikan objek fisiknya tetapi juga objek digital serta nilai informasinya. Perpustakaan belum melakukan kontrol kualitas terhadap koleksi digital. Hal tersebut dapat dilihat dari pengelolaan CD skripsi dan tesis. Kontrol terhadap media penyimpanan hardisk eksternal dan server telah dilakukan. Tindakan UPT Perpustakaan Unsoed menjamin preservasi jangka panjang dengan melakukan kegiatan penyimpanan data secara berjenjang, yaitu di server aplikasi E-doc dan hardisk eksternal. Pelestarian masih sebatas pada objek digital dengan mem-backup onsite yang tidak berada pada kustodian lain (offsite).

Kegiatan preservasi membutuhkan kesiapan aspek hukum, SOP, pedoman dan alur kerja serta ketersediaan sarana prasarana. UPT Perpustakaan Unsoed saat ini belum memberikan perhatian khusus pada koleksi digital dan belum memiliki acuan kerja terkait pengelolaan koleksi digital. Namun, saat ini perpustakaan telah menginisiasi aspek legal formal dalam pengelolaan koleksi digital, misalnya dengan menerbitkan surat pemberitahuan penerimaan skripsi dan tesis dalam format PDF dan tidak lagi menerima skripsi dalam bentuk cetak. 
Jumlah CD yang semakin meningkat tiap tahun harus disikapi dengan penanganan preservasi yang tertuang dalam SOP dan diperkuat dengan dasar hukum yang jelas. Saat ini, media CD ditempatkan dalam tempat yang memuat banyak CD lalu dimasukkan ke dalam lemari dengan urutan pertahun di ruang perpustakaan.

Berikut ini ada beberapa langkah yang perlu menjadi rujukan perpustakaan dalam mengurangi/mencegah tingkat kerusakan pada media digital (Perpustakaan Nasional RI, 2014).

a) Pengontrolan lingkungan tempat penyimpanan media digital, pengaturan suhu pada tempat penyimpanan. Digital Preservation Division National Library of Australia melakukan penelitian terkait usia pemakaian media digital berdasarkan temperatur (Tabel 2).

Tabel 2. Usia Pemakaian Media Digital Berdasarkan Temperatur

\begin{tabular}{|l|c|c|c|c|c|}
\hline \multicolumn{1}{|c|}{ Device } & $\mathbf{2 5 R H}$ & $\mathbf{3 0 R H}$ & $\mathbf{4 0 R H}$ & $\mathbf{5 0 R H}$ & $\mathbf{5 0 R H}$ \\
\hline D3 magnetic tape & 50 tahun & 25 tahun & 15 tahun & 3 tahun & 1 tahun \\
\hline $\begin{array}{l}\text { DLTmagnetc tape } \\
\text { cartridge }\end{array}$ & 75 tahun & 40 tahun & 15 tahun & 3 tahun & 1 tahun \\
\hline CD/DVD & 75 tahun & 40 tahun & 20 tahun & 10 tahun & 2 tahun \\
\hline CD-ROM & 30 tahun & 15 tahun & 3 tahun & 9 bulan & 3 bulan \\
\hline
\end{tabular}

Sumber: Digital preservation division - National Library of Australia (2005)

UPT Perpustakaan Unsoed saat ini belum mempunyai ruang khusus penyimpanan CD yang disertai dengan pengatur suhu sehingga berdampak pada kondisi fisik CD cepat rusak. Dapat dipastikan bahwa koleksi CD perpustakaan sudah mengalami kerusakan fisik yang menyebabkan informasi didalamnya tidak dapat diakses.

b) Membuat sistem backup terhadap file. Backup koleksi skripsi dan tesis UPT Perpustakaan Unsoed hanya menggunakan hardisk eksternal atau backup file (onsite). Sistem penyimpanan berbasis web $E$-doc juga berfungsi sebagai aplikasi layanan pengaksesan koleksi sehingga kurang ideal dikategorikan sebagai backup. Pedoman teknis dan schedule backup tidak tertuang dalam SOP, namun hanya berdasarkan insiatif petugas.

c) Preservasi teknologi, merupakan tindakan perawatan, penyimpanan, dan pendokumentasian original software dan hardware yang dipakai dalam pembuatan berkas digital. Acuan kerja yang tertuang dalam SOP UPT Perpustakaan Unsoed belum menggambarkan tindakan preservasi teknologi. Tindakan ini bersifat atas dasar inisiatif petugas.

d) Pembaharuan atau penyegaran, yaitu pemindahan data dari satu media ke media lain dengan memperhatikan usia media. Skripsi dan tesis tidak dipindahkan ke media yang sama sebagai tindakan penyegaran tetapi dipindahkan ke hardisk eksternal dan server aplikasi. Kegiatan ini sebagai upaya menjaga ketahanan koleksi digital UPT Perpustakaan Unsoed.

e) Migrasi dan format ulang, yaitu format ulang data agar sesuai dengan versi terbaru dari hardware dan software komputer. Perpustakaan melakukan migrasi sebelum penerbitan surat pemberitahuan Kepala UPT Perpustakaan tahun 2017 tentang penyerahan CD dan skripsi. Awalnya skripsi dan tesis diserahkan dalam bentuk Word (.doc, docx) sehingga perpustakaan perlu mengkonversi file ke PDF sebelum diunggah ke website. Pada Januari 2017, penyerahan CD skripsi dalam format PDF sehingga tidak perlu dimigrasi ke bentuk yang lain.

f) Perencanaan sistem komputer yang matang dan berdasarkan kebutuhan, serta adanya proses penyegaran pada lingkungan sistem operasi komputer dan platform komputer. Perpustakaan tidak melakukan pembuatan ulang secara berkala program komputer tertentu 
agar dapat terus membaca data digital yang tersimpan di dalam berbagai format dari berbagai versi.

g) Arkeologi digital, merupakan usaha untuk menyelamatkan isi dokumen yang tersimpan dalam media penyimpanan yang sudah rusak agar dapat digunakan kembali. Biaya kegiatan ini dikategorikan rendah tetapi memiliki resiko tinggi. Kegiatan dalam strategi ini hanya memperbaharui media penyimpanannya dan kemungkinan data tersebut tidak terbaca ketika ada teknologi yang baru. Apabila ada kerusakan file di server dan backup data disimpan di hardisk eksternal atau CD. Penyimpanan CD yang tidak sesuai dengan standar temperatur sehingga menyebabkan $\mathrm{CD}$ dalam kondisi fisik rusak, tergores, atau berjamurperlu dilakukan preservasi media penyimpanan, seperti menggunakan cairan pembersih CD.

h) Mengubah data digital menjadi analog (tercetak), terutama untuk materi digital yang sulit diselamatkan. Dalam hal ini, UPT Perpustakaan tidak mengubah data digital menjadi analog.

\section{Store}

Pemindahan objek digital ke media penyimpanan dan kustodian harus terencana dan terdokumentasi. UPT Perpustakaan Unsoed melakukan tindakan jangka panjang untuk memastikan data tetap aman dengan mem-backup seluruh koleksi digital ke hardisk eksternal. Tindakan penyegaran media penyimpanan tidak dapat dipastikan karena bergantung pada anggaran. Perpustakaan belum memiliki jadwal yang tertulis dalam bentuk acuan kerja untuk melakukan kegiatan mengecek perangkat keras penyimpanan, menyegarkan media, dan membuat salinan cadangan. Kesiapan untuk mengantisipasi kemungkinan kerusakan media, kehilangan data karena faktor alam atau batas usia media penyimpanan belum menjadi prioritas.

Menurut ahli bidang transformasi digital Perpustakaan Nasional RI dalam wawancara penelitian mengatakan bahwa "penyimpanan koleksi digital, baik dalam rangka preservasi maupun menjamin ketersediaan koleksi, sebaiknya dibuatkan data centre yang mampu menampung seluruh koleksi yang bersifat lokal ataupun tidak terhubung dengan internet/terpisah dari aplikasi layanan". Terkait hal tersebut, UPT Perpustakaan Unsoed belum memiliki data centre sebagai penyimpanan koleksi digital.

\section{Access Use and Reuse}

E-doc (edoc.unsoed atau IP addresss http://192.168.30.232) dan Izylib (http://lib.unsoed.ac.id) merupakan aplikasi OPAC yang melayankan koleksi skripsi dan tesis. Perbedaan dari aplikasi E-doc dan Izylib terletak pada akses file PDF. Izylib terbatas pada penelusuran, tidak dapat mengakses file PDF sedangkan E-doc dapat digunakan untuk menelusur dan memberikan layanan pengunduhan file PDF skripsi dan tesis. Aplikasi Izylib sudah online sedangkan $E$-doc masih bersifat local yang hanya bisa diakses melalui komputer yang telah disediakan. Persamaan kedua aplikasi tersebut yaitu dapat memunculkan metadata deskriptif dan memastikan pelestarian metadata.

Proses diseminasi content masih terbatas pada lingkungan UPT Perpustakaan Unsoed. Berbeda dengan repositori institusi yang sudah di layankan secara online dan berdampak pada peningkatan webomatric lembaga. E-doc sebagai aplikasi OPAC dapat memberikan fasilitas unduh file full text namun dalam praktiknya masih perlu dievaluasi. Fitur search E-doc tidak terdapat filter pencarian berdasarkan program studi, fakultas, atau tahun. Gambar 2 
menjelaskan tampilan database Izylib dan Gambar 3 tampilan database E-doc.
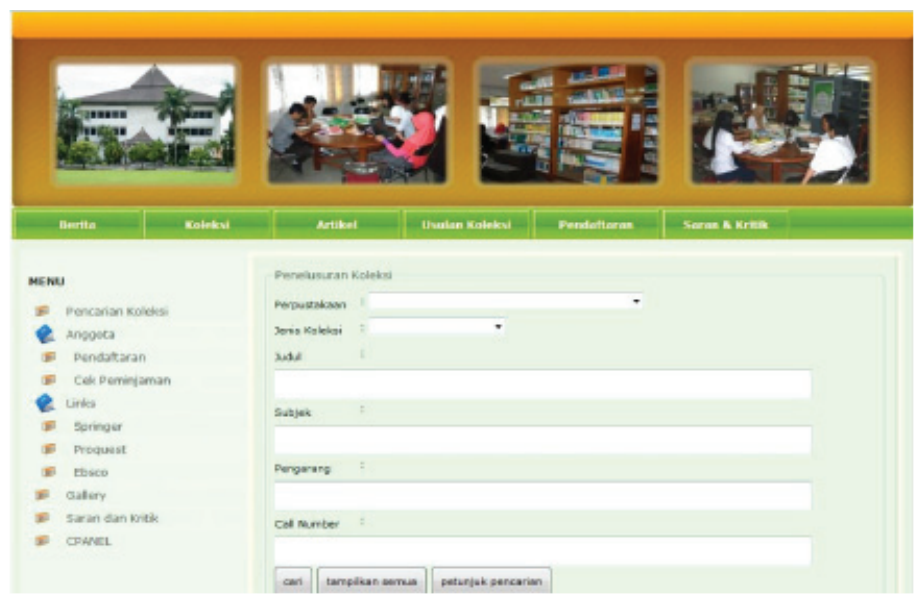

Gambar 2. Halaman pencarian aplikasi Izylib

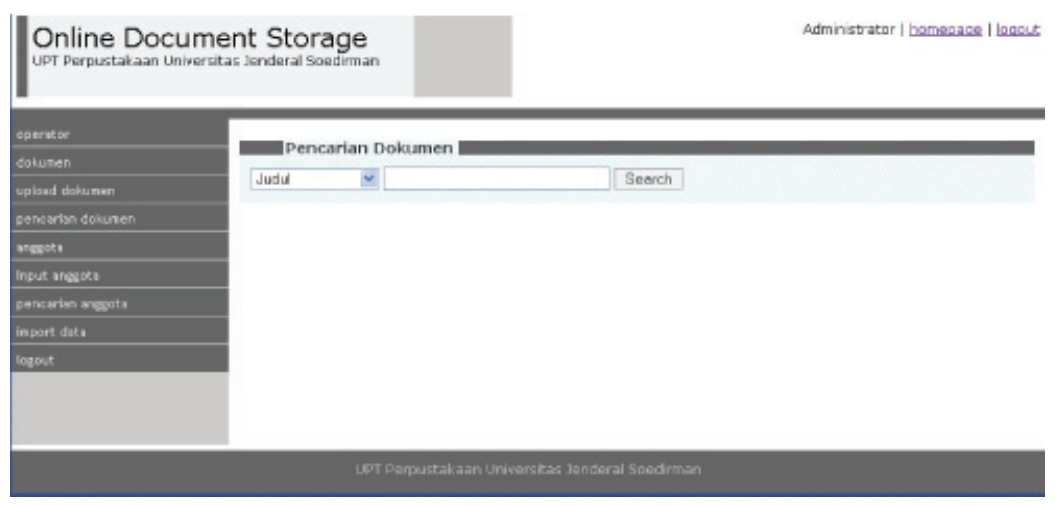

Gambar 3. Halaman pencarian aplikasi E-doc

\section{Transform}

UPT Perpustakaan Unsoed belum melakukan transformasi objek digital dari PDF ke objek yang berbeda. Untuk itu perlu diimbangi dengan ketersediaan software dan tools untuk membuka file, baik file yang tersimpan dalam bentuk .zip, .rar, atau .iso untuk menjaga keberlangsungan jangka panjang koleksi. Alih media atau transform dapat mengubah ukuran yang lebih kecil sehingga akan memperingan proses backup data dan mengantisipasi resiko corrupted file dan malware.

\section{KESIMPULAN}

Berdasarkan hasil penelitian dapat disimpulkan bahwa UPT Perpustakaan Unsoed sudah melakukan kegiatan digital curation. Beberapa hambatan dalam digital curation mencakup aspek legal formal (hukum) terkait dengan pelaksanaan siklus belum kuat, SOP kadaluwarsa, tidak adanya pedoman teknis, sarana prasarana, serta kurangnya pemahaman pustakawan terhadap digital curation. Selain itu, ada beberapa tahapan dalam digital curation yang pelaksanaannya belum optimal, seperti create or receive, appraise and select, preservation action, store dan transform. 


\section{DAFTAR PUSTAKA}

Ball, A. 2010. Review of the State of the Art of the Digital Curation of Research Data. UK: University of Bath.

Digital Preservation Handbook. 2017. Di http://www.dpconline.org/handbook/glossary (akses 29 Oktober 2017).

Dublin Core Metadata Element Set, Version 1.1: Reference Description. 2013. Di http://dublincore.org/documents/dces/ (akses 29 Oktober 2017).

Fathoni, A. 2006. Metodologi Penelitian \& Teknik Penyusunan Skripsi. Jakarta: Rineka Cipta.

Higgins, Sarah. 2011. Digital Curation: The Emergence of a New Discipline. The International Journal of Digital Curation, Issue 2, Volume 6.

Meekin, S Mc. 2011. With a Little Help from OAIS: Starting down the Digital Curation Path. Journal of the Society of Archivists, 241-253.

Miles, H dan Saldana. 2014. Qualitative Data Analisis A Methods Sourcebook. USA: Sage Publication.

Moleong, L.J. 2017. Metode Penelitian Kualitatif, ed.rev. Bandung: PT. Remaja Rosdakarya.

Narendra, Al. Pramukti. 2014. Digital Curation (Kurasi digital) Perpustakaan Nasional Republik Indonesia Wujud Pelestarian Kekayaan Budaya Bangsa. Journal Libraria, Vol.3, No.1.

Nawawi, Hadari. 2007. Metode Penelitian Bidang Sosial. Yogyakarta: Gadjah Mada University Press.

Pennock, Maureen. 2007. Digital Curation: A Life-Cycle Approach to Managing and Preserving Usable Digital Information. UK: University of Bath.

Perpustakaan Nasional RI. 2014. Pedoman Pembuatan E-Book dan Standar Alih Media. Jakarta.

Perpustakaan Nasional RI. 2014. Standar Operasional Prosedur Alih Media Digital Bidang Transformasi Digital. Jakarta.

Płoszajski, Grzegorz. "Metadata in Long-Term Digital Preservation". Di http://www.springer.com/cda/content/document/cda_downloaddocument/9783319518008c2.pdf?SGWID=0-0-45-1599380-p180541233 (akses 29 Oktober 2017).

Priyanto, Ida Fajar. 2013. Digital Curation: Personal Perception, Overview, and Reality. College of Information. Texas: University of North Texas.

Sugiyono. 2007. Metode Penelitian Kuantitatif, Kualitatif dan $R \& D$. Bandung: Alfabeta.

Tim Universitas Jenderal Soedirman. 2011. Standar Operating Procedures (SOP) UPT Peprustakaan, UPT Pusat Komputer, UPT Pemberdayaan Fasilitas, UPT Penerbitan dan Percetakan. Purwokerto: Universitas Jenderal Soedirman. 